\title{
Awareness of Foot Care Among Patients with Diabetes Mellitus attending a Tertiary Care Hospital
}

\author{
Dr.P.Ganesh Kumar, MS., Dr. P. Venkateswaran MS., and Damini.T
}

Government Villupuram Medical College, Tamil Nadu.

Received 04 Feb 2018, Accepted 05 April 2018, Available online 08 April 2018, Vol.6 (March/April 2018 issue)

\begin{abstract}
Objective: To assess the awareness of diabetes foot and care for foot in known diabetic patients.

Methods: A cross- sectional study was carried out using non probability convenience sampling wherein 150 diabetic respondents who fulfilled the inclusion criteria were included. A pre tested questionnaire was used to assess their knowledge and practices regarding foot care. 14 questions were asked and one point was allotted for each of 7 questions among them. A score of more than 70\% (5-7) was considered good, score of 40\% - 70\% (3-5) was considered satisfactory and less than $40 \%$ (below 3 ) was considered poor.

Results: The age of the respondents selected was above 50 years. About $48.7 \%$ of the respondents had good awareness, $38.6 \%$ had satisfactory awareness and $12.7 \%$ had poor awareness. Literacy status of the respondents seems to have a significant association with their awareness. Economic status is not a significant factor.
\end{abstract}

Keywords: Diabetic patients etc.

\section{Introduction}

The prevalence of Diabetes has risen to epidemic proportions in India [1]. Diabetic foot problems such as ulcerations, infections and gangrene are the most common complications of diabetes among patients responsible for hospitalization. It is also the major cause for non traumatic amputation of lower extremity. Approximately $14-24 \%$ of the patients with diabetic foot ulcer require amputation [2].

The majority of ulcers result from minor trauma in the presence of peripheral neuropathy. The triad of "peripheral sensory neuropathy, deformity and trauma" is seen in patients with foot ulcer [3].

Formation of advanced glycosylated end products, oxidative stress and activation of protein kinase $C \beta$ are said to be the reason for peripheral neuropathy. In addition many studies have confirmed the pivotal role of hyperglycemia in the onset and progression of neuropathy. Smoking plays a major role in the pathogenesis of Diabetic foot ulcer. Diabetes is becoming a disease of the poor living in urban areas in well developed states of India [4] According to International Diabetes Federation (IDF) one in three or $33 \%$ of the people above 30 years of age are suffering from lifestyle diseases such a diabetes, high blood pressure,

*Corresponding author's ORCID ID: 0000-0002-8954-0227, DOI: https://doi.org/10.14741/ijmcr/v.6.2.8 cholesterol, thyroid and cancer [5]. Diabetes is more common in people of higher socio economic class than those in lower socioeconomic class. Diabetes is twice as common in urban areas than in rural areas [6].

To date, diabetic foot ulcer is considered the major source of morbidity and hospital admission in patients with diabetes mellitus. Diabetic foot ulcer can cause infection, gangrene, amputations and even death if proper care is not given. Approximately $50 \%$ to $70 \%$ of the foot amputations are due to diabetes foot ulcer [7].

Owing to the importance of diabetic foot problems, IDF had chosen "Put feet first, prevent amputations" as the theme for World Diabetes day in 2005 [8]. Certain guidelines are to be followed by diabetic persons according to American Diabetes Association. This study aims at assessing the knowledge and practices among the diabetic patients regarding foot care.

\section{Methods}

A cross-sectional study was conducted in outpatient and inpatient departments of Government Villupuram Medical college, Mundiyapakkam, Tamil Nadu. Prior proper ethical committee clearance was obtained from our college medical education unit. The inclusion criteria include patients with diabetes mellitus above 50 years of age. Sample size was calculated through computer software program Epi info 6.2. The minimum representative sample was 150 but 200 respondents had 
been taken. Non probability convenience sampling method was used. The respondents were interviewed with pre-tested questionnaire after verbal consent with 14 questions about their awareness of diabetic foot and its care. The dependent variable of the study was awareness about diabetic foot and its care. The independent variables are education and monthly income. SPS Version 11 was used for analyzing the data. Simple frequency distribution table were generated and chi square test was applied to find out whether there is any statistical significance between socio economic factors and awareness about foot care. 14 questions were asked and 7 of them were taken to assess the awareness. Yes for each of the 7 questions were allotted 1 point.

\section{Good awareness : if more than 70\% (5-7) \\ Satisfactory : : if more than $40 \%(3-5)$ \\ Poor : if less than $40 \%(<3)$}

\section{Results}

A total of 150 respondents were interviewed. The respondents were patients with diabetes mellitus over 50 years of age. Of the 150 respondents 56 (37.3\%) of them were male and 94 (62.7\%) were females. 98 of them are diabetics for less than 5 years. 119 of them were on oral hypoglycaemic drugs and 20 of them were on both drugs and insulin injection. 70\% (105 of them) had monthly income above rs.1000 INR. 87.1\% were non smokers. $77.4 \%$ do monitor their blood glucose regularly. Awareness about the use of footwear outside the house is about $93.3 \%$.

Table 1: Questions determining the awareness about foot care

\begin{tabular}{|c|c|c|}
\hline $\begin{array}{c}\text { Questions asked to assess the } \\
\text { awareness }\end{array}$ & Yes & no \\
\hline $\begin{array}{c}\text { 1. Do you inspect your feet daily } \\
\text { and look for any red spots/ cuts/ } \\
\text { swelling/ blisters? }\end{array}$ & $127(84.7 \%)$ & $23(15.3 \%)$ \\
\hline $\begin{array}{c}\text { 2. Do you wash your feet daily } \\
\text { with soap and water? }\end{array}$ & $137(91.3 \%)$ & $13(8.7 \%)$ \\
\hline $\begin{array}{c}\text { 3. Do you keep your inter-digital } \\
\text { spaces clean and dry? }\end{array}$ & $120(80 \%)$ & $30(20 \%)$ \\
\hline $\begin{array}{c}\text { 4. Do you regularly trim and clip } \\
\text { your nails? }\end{array}$ & $132(88 \%)$ & $18(12 \%)$ \\
\hline 5. Do you wear slippers outdoor? & $140(93.3 \%)$ & $10(6.7 \%)$ \\
\hline 6. Do you smoke? & $131(87.3 \%)$ & $19(12.7 \%)$ \\
\hline $\begin{array}{c}\text { 7. Do you regularly monitor your } \\
\text { blood glucose level? }\end{array}$ & $117(78 \%)$ & $33(22 \%)$ \\
\hline
\end{tabular}

Table 2 : Results of the survey

\begin{tabular}{|c|c|}
\hline Scoring out of 7 & Results \\
\hline Good $:>70 \%(5-7)$ & $73(48.7 \%)$ \\
\hline Satisfactory $:>40 \%(3-5)$ & $58(38.6 \%)$ \\
\hline Poor $:<40 \%(<3)$ & $19(12.7 \%)$ \\
\hline
\end{tabular}

Table 3 : Results of significance of independent variables such as Educational status, gender and income

\begin{tabular}{|c|c|c|c|}
\hline Variable & \multicolumn{3}{|c|}{} \\
\hline Education level & $>70 \%$ & $40 \%-70 \%$ & $<40 \%$ \\
\hline literate & $32.3 \%$ & $16.1 \%$ & $3.2 \%$ \\
\hline Illiterate & $16.1 \%$ & $25.8 \%$ & $9.7 \%$ \\
\hline \multicolumn{3}{|c|}{ (P Value = 0.02204) } \\
\hline Gender & $22.6 \%$ & $12.9 \%$ & $6.5 \%$ \\
\hline Male & $25.8 \%$ & $25.8 \%$ & $6.5 \%$ \\
\hline Female & (P value $=0.231618)$ \\
\hline \multicolumn{3}{|c|}{} \\
\hline $\begin{array}{c}\text { Income } \\
\text { (monthly) }\end{array}$ & $29 \%$ & $16.1 \%$ & $0 \%$ \\
\hline > rs. 1000 & $19.4 \%$ & $22.6 \%$ & $12.9 \%$ \\
\hline <rs. 1000 & (P Value $=0.662639)$ \\
\hline \multicolumn{3}{|c|}{} \\
\hline
\end{tabular}

Literacy has significant association with the awareness ( $p$ value $=0.02204)$. Gender did not have any significant association ( $p$ value $=0.231618$ ). Similarly income of the patient does not any have any impact on the awareness about foot care ( $p$ value $=0.662639)$.

\section{Discussion}

The study results revealed that awareness about foot care among diabetes patients is still on the rise and has not effectively reaches desired levels. $19 \%$ of the respondents have poor awareness. Diabetes is associated with musculoskeletal and systemic complications and the most common being diabetic foot ulcers [9]. Among the 52\% amputations in diabetic patients, $80 \%$ of it are due to foot ulcers and this is being on rise.With diabetes being on rise in India more concentration is necessary on the effects of diabetes. Diabetic foot care is the most dreadful complication which can be prevented by simple low cost methods. One other feature in the study is that some of the people do have awareness and practices without very good literacy state. This means that some people follow good practices without knowing its beneficial effects. This maybe because of the regular routine practices of the people which they perform without knowing they do form a part of the good foot care practices. 93\% of the people wear footwear outside the house. Owing to the culture and socioeconomic background of a southern Indian state like Tamil Nadu this is a sign of positive effect. This can be partly attributed to the minimum education of the people and to the awareness created by health personnel and mass media. According to an article from Pakistan published in 2009 in foot care knowledge and practices there was a significant gap between knowledge and practices [10]. This gap is being bridged in recent years and complete bridging of it requires involvement of all the medical care providers, health care personnel from Village Health Nurses to doctors and para medics. More diabetic centres and mobile units should be created. Public awareness requires mass media and electronic and print materials to be utilized efficiently. 


\section{Acknowledgement}

The author expresses her sincere gratitude to Dr. P. Ganesh Kumar MS., Assistant Professor, Department of Surgery, Government Villupuram Medical College for his valuable help and encouragement in completing this study. I also thank Dr. P. Venkateswaran sir, Head of the department, Department of General surgery Government Villupuram Medical college for giving me full support to complete this successfully. I thank Prof. Dr. Anandi Andappan for encouraging me intiate this study. I am grateful to the college administration for letting me conduct this study. I thank my colleagues for helping me collect the data.I thank all the patients who had the patience and time to participate in the study. I also thank my parents for their support and last but not the least I thank the Almighty for all the blessings.

\section{References}

[1]. Mohan V, Mathur P, Deepa R, Shukla DK, Menon GR et al. Urban rural differences in prevalence of self reported diabetes in India - the WHO- ICMR Indian NCD risk factor surveillance, Diabetes Res Clin Pract 2008;80:159-68
[2]. http://clinical.diabetesjournals.org/content/24/2/9

[3]. McNeely MJ, Boyko EJ, Ahroni JH, Stensel VL, Reiber GE, Smith DG, Pecoraro RF: The independent contributions of diabetic neuropathy and vasculopathy in foot ulceration: how great are the risks?Diabetes Care18 : 216-219,1995

[4]. https://everylifecounts.ndtv.com/diabetes-rise-amongurban-poor-india-shows-global-study-14072

[5]. https://www.idf.org/our-network/regions-members/southeast-asia/south-east-asia-news.html

[6]. Leone S, Pascale R, Vitale M, Esposito S

[7]. Infez Med. 2012; 20 Suppl 1():8-13.

[8]. Jawaid SA, Jawaid M. Management of diabetic foot ulcers; some bitter facts and harsh realities. Pak J Med Sci 2006; 22: $97-100$

[9]. Viswanathan V, Madhavan S, Rajasekar S, Chamukuttan S, Ambady $R$ (2006) Urban-rural differences in the prevalence of foot complications in South-Indian diabetic patients. Diabetes Care 29: 701-703.

[10]. Knowledge and practices regarding foot care in diabetes patients visiting diabetic clinic in Jinnah hospital, Lahore by Seema Hasnain and Naheed Humayun Sheik, Department of community medicine, Allama Iqbal Medical College, Lahore. 